\title{
Economical, Green, and Safe Route Towards Substituted Lactones by Anodic Generation of Oxycarbonyl Radicals
}

\author{
Alessia Petti ${ }^{[a]}$, Matthew C. Leech ${ }^{[a]}$, Anthony D. Garcia ${ }^{[a]}$, lain C. A. Goodall ${ }^{[a]}$, Adrian P. Dobbs ${ }^{[a]}$; and \\ Kevin Lam*[a]
}

\begin{abstract}
:
A new electrochemical methodology has been developed for the generation of oxycarbonyl radicals under mild and green conditions from readily available hemioxalate salts. Mono- and multifunctionalised $y$-butyrolactones were synthesised through exo-cyclisation of these oxycarbonyl radicals with an alkene, followed by the $s p^{3}-s p^{3}$ capture of the newly formed carbon-centred radical. The synthesis of functionalised caprolactone derivatives was also achieved, demonstrating the versatility of the newly developed methodology. This represents a viable synthetic route towards pharmaceutically important fragments and further demonstrates the practicality of electrosynthesis as a green and economical method to activate small organic molecules.
\end{abstract}

Electrochemistry has long been a useful synthetic tool in organic chemistry, with examples as early as $1832 . .^{[1,2]}$ With the introduction of more readily available electrosynthesis equipment,,$^{[3,4]}$ electrosynthesis has experienced a resurgence in interest, ${ }^{[5-12]}$ and has proven to possess diverse applications such as the allylic oxidation of alkenes, ${ }^{[9]}$ fluorination of $s p^{3}$ carbon centres, ${ }^{[11]}$ cathodic radical deoxygenation, ${ }^{[12]}$ electrochemical methoxymethylation, ${ }^{\left[{ }^{6]}\right.}$ and oxidative decarboxylation. ${ }^{[8]} \quad$ Furthermore, these electrochemical transformations have been successfully transposed to an industrial scale. ${ }^{[9,13]}$

Compounds containing $\mathrm{y}$-butyrolactone fragments exhibit varied uses, for example as fungicidal, ${ }^{[14]}$ antibiotic, ${ }^{[15,16]}$ and anticancer agents ${ }^{[17,18]}$ and therefore are of particular interest in the pharmaceutical industry. ${ }^{[19-21]}$ As a result, numerous synthetic strategies have been developed to assemble substituted lactones rapidly and in good yields. ${ }^{[20]}$ Generally, these procedures rely on the use of expensive and toxic metal catalysts at high loadings (ca. $5 \mathrm{~mol} \%$ to multiple equivalents) based on copper, ${ }^{[22,23]}$ ruthenium, ${ }^{[15,24]}$ palladium, ${ }^{[25]}$ or iridium $^{[26,27]}$ in order to increase yields, and with the exception of halolactonisation, ${ }^{[28]}$ examples of metal-free reactions remain rare. ${ }^{[29,30]}$ Unfortunately, these approaches are not ideal due to their reliance on expensive and potentially toxic metal catalysts and undesirable solvents, especially within a pharmaceutical environment.

The use of photochemical methods to generate acyl radicals is well established, with a wide variety of photocatalysts and substrates utilised. ${ }^{[27,31-33]}$ In contrast, the generation of acyl radicals using electrochemical methods remains scarcely

[a] A. Petti, Dr M. C. Leech, , A. D. Garcia, Dr I. C. A. Goodall, Prof. Dr A. P. Dobbs, Dr K. Lam

Department of Pharmaceutical, Chemical and Environmental

Sciences, Faculty of Engineering and Science

University of Greenwich,

Chatham Maritime, Chatham, Kent, ME4 4TB (UK)

E-mail:k.lam@greenwich.ac.uk

Supporting information and the ORCID identification number(s) for the author(s) of this article can be found under:

https:// explored. ${ }^{[34,35]}$ This is perhaps surprising considering that the latter is significantly cheaper ( $1 \mathrm{~mol}$ of electrons costs $\approx$ $£ 0.83 / € 0.93$ vs $£ 60-140 / € 67-156$ per $100 \mathrm{mg}$ of commercially available iridium-based photocatalysts), ${ }^{[36,37]}$ less toxic, greener, and easier to scale-up to industrial scale. ${ }^{[9]}$ With this in mind, we have previously employed aroyloxy radicals, formed via anodic oxidation of aromatic carboxylic acids, to synthesise a library of functionalised phthalides under mild and green conditions. ${ }^{[38]}$

While the photochemical synthesis of $\mathrm{y}$-butyrolactones has recently been reported, this methodology relies on highly toxic and expensive solvent mixtures and metal catalysts. Moreover, it is currently limited to $s p^{2}-s p^{3}$ coupling cascades and requires the use of a caesium salt. ${ }^{[2]}$ Through an adaptation of our previously reported electrochemical methodology, we seek to complement this study and hereby report the synthesis of various substituted $\mathrm{Y}$-butyrolactones from alcohol-derived hemioxalates using an unusual free radical $s p^{3}-s p^{3}$ crosscoupling.

Initial studies utilised the hemioxalate ammonium salt $\mathbf{1}$. While attempts to electrolyse the precursors, under their acidic hemioxalate form, afforded the desired outcome, their inherent instability precluded reproducibility. While other reports propose the use of caesium salts, ${ }^{[27]}$ the synthetic routes can be long and non-trivial, whereas the corresponding ammonium salts are significantly cheaper, faster and easier to prepare, and lead to $\mathrm{CO}_{2}$ and $\mathrm{NH}_{3}$ as the volatile by-products of the reaction. Furthermore, cyclic voltammetry studies have shown the expected chemically and electrochemically irreversible oxidation and suggested that these salts can be oxidised at reasonably low potentials compared to usual aliphatic acids $(\approx 0.9 \mathrm{~V}$ vs Fc). ${ }^{[39]}$

Aliphatic carboxylic co-acids were chosen as coupling partners since they are known to undergo anodic decarboxylation. Furthermore, they provide a cheap and readily available source of alkyl radicals which undergo an unusual metal-free $s p^{3}-s p^{3}$ cross-coupling at the surface of the electrode (Table 1). ${ }^{[38]}$ After optimisation, ${ }^{[40]}$ it was found that the substituted lactone 2 was formed in higher yields (30\%) when 1 was added to a methanolic solution of co-acid and potassium hydroxide, with no lactone formation observed in DMF or acetonitrile. Alcohols, water, as well as mixtures of both are known to favour the mono-electronic anodic oxidation of carboxylic acids while other solvents tend to favour a bielectronic oxidation. ${ }^{[13]}$ Platinum has shown to be the most appropriate electrode material for the reaction. As an anode, platinum limits the adsorption of the oxidation products and therefore avoids an overoxidation of the radical into a carbocation. As a cathode, the low hydrogen overvoltage of platinum favours the reduction of a proton (from the solvent, the ammonium or the co-acid) and therefore avoids any undesired cathodic side-reactions. On the contrary, carbon graphite was found to be unsuitable (see Table $S 1$ in the supporting information) due to its high hydrogen overvoltage and to the fact that it strongly adsorbs organic substrates. No increase in yield was observed upon modification of the reaction temperature, nor 
upon exchange of $\mathrm{KOH}$ for other common bases. Remarkably, deoxygenating or drying the electrolysis solvent had no impact on the yields. Also, addition of $\mathbf{1}$ to the reaction mixture in six portions over a one-hour period assisted in maintaining a low concentration in hemioxalate, which was necessary since, as shown during our cyclic voltammetry studies, $\mathbf{1}$ is easier to oxidise than the aliphatic co-acid.

Table 1. Anodic Lactonisation Optimisation Conditions ${ }^{[a][b]}$<smiles>C=CCCOC(=O)C(=O)ON</smiles>
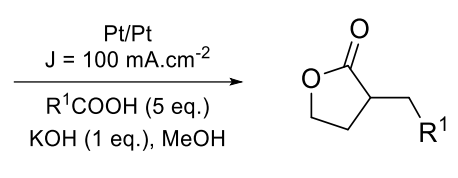

\begin{tabular}{ccccc}
\hline Entry & Base & Solvent & Temperature & Yield $^{[a][b]}$ \\
\hline 1 & $\mathrm{KOH}$ & $\mathrm{MeOH}$ & $\mathrm{RT}$ & $35 \%$ \\
2 & $\mathrm{KOH}$ & $\mathrm{MeOH}$ & $0^{\circ} \mathrm{C}$ & $22 \%$ \\
4 & $\mathrm{KOH}$ & $\mathrm{MeOH}$ & $50^{\circ} \mathrm{C}$ & $11 \%$ \\
5 & $\mathrm{NaOMe}$ & $\mathrm{MeOH}$ & $\mathrm{RT}$ & $23 \%$ \\
6 & $\mathrm{KOH}$ & $\mathrm{DMF}$ & $\mathrm{RT}$ & $0 \%$ \\
7 & $\mathrm{Pyridine}$ & $\mathrm{DMF}$ & $\mathrm{RT}$ & $0 \%$ \\
8 & $\mathrm{KOH}$ & $\mathrm{MeCN}$ & $\mathrm{RT}$ & $0 \%$ \\
9 & $\mathrm{Et}{ }_{3} \mathrm{~N}$ & $\mathrm{MeCN}$ & $\mathrm{RT}$ & $0 \%$ \\
\hline
\end{tabular}

[a] Reaction conditions: $0.6 \mathrm{mmol}(1), 5$ eq. $\mathrm{R}^{1} \mathrm{COOH}\left(\mathrm{R}^{1}=\mathrm{H}_{3} \mathrm{C}\left(\mathrm{CH}_{2}\right) 7\right), 1$ eq. $\mathrm{KOH}, \mathrm{MeOH}$, Pt foil working electrode, Pt-plated counter electrode, 100 $\mathrm{mA} . \mathrm{cm}^{-2}, 10 \mathrm{~F} \mathrm{~mol}^{-1}, \mathrm{RT}, 56 \mathrm{~min}$. [b] Yield determined by ${ }^{1} \mathrm{H} \mathrm{NMR}$ spectroscopic analysis of the crude mixture using $\mathrm{CH}_{2} \mathrm{Br}_{2}$ as an internal standard.

A possible mechanism for the electrochemically induced cyclisation-cross-coupling is outlined in Scheme 1 . The formation of the lactone is the outcome of at least five individual events that are occurring at both electrodes: (1) the Initial oxidation of the hemioxalate salt results in decarboxylation to form an oxycarbonyl radical (A), (2) which rapidly undergoes a 5-exo-trig cyclisation to form a five-membered ring and a new carbon-centred $\mathrm{CH}_{2}$ radical (B). (3) Concurrently, deprotonation of the co-acid (forming C in-situ) and (4) subsequent decarboxylation results in large quantities of alkyl radicals $\left(R^{*}\right)$, (5) which recombine with the cyclised radical $\mathbf{B}$ to form the desired lactone. This synthetic approach takes advantage of the unique properties of electrochemical synthesis, namely the ability to create high concentrations of radicals near or at the electrode's surface. ${ }^{[41][42]}$ This leads to radical recombination, which is not usually possible using classical homogenous methodologies.

Conveniently, only small quantities of base are required for deprotonation since the electrolysis produces large amounts of methoxide ions from the reduction of the solvent, which acts in place of hydroxide. An excess of co-acid is required in order to prevent homo-dimerisation of the cyclised radical. However, a direct consequence of this is that the main by-product of the reaction is the R-R dimer. Nevertheless, these compounds are either volatile or easily removed by chromatography over silica gel.

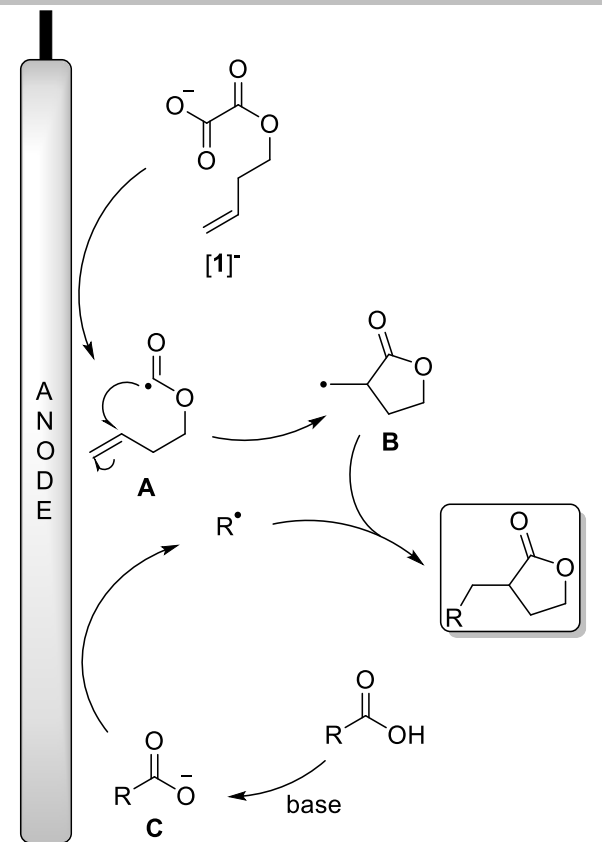

Scheme 1. A plausible mechanism for anodic lactonisation of hemioxalate salts.

With the optimal electrolysis conditions in hand, the scope and limitations of the newly developed methodology were investigated by electrolysing 1 in presence of different aliphatic co-acids (Scheme 2). Moderate isolated yields of lactone $\mathbf{3}$ were obtained due to the high volatility of these compounds, resulting in significant losses upon purification. ${ }^{[43]}$ However, in general, the NMR spectroscopic data of the crude mixture show a clean reaction, suggesting that pursuing further synthetic steps without purification is feasible. 


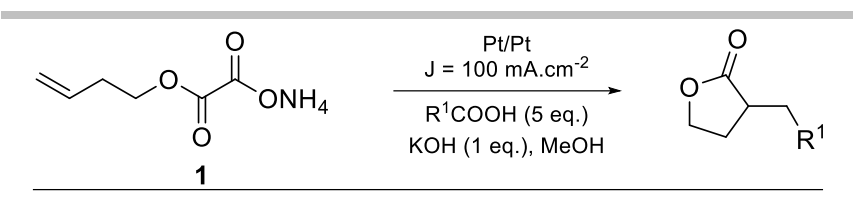

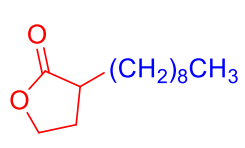

2

$30 \%(24 \%)$<smiles>CC(C)CC1CCOC1=O</smiles>

5

$73 \%(24 \%)$

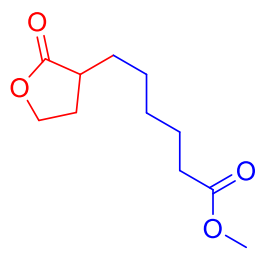

8

$40 \%(35 \%)$

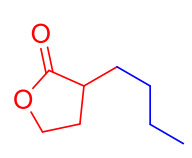

3

$$
83 \%(46 \%)
$$<smiles>CC(C)(C)CC1CCOC1=O</smiles>

6

$69 \%(36 \%)$<smiles>COC(=O)CCCC1CCOC1=O</smiles>

9

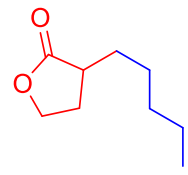

4 $47 \%(24 \%)$<smiles>O=C1OCCC1CCl</smiles>

7 $35 \%(20 \%)$
Scheme 2. Anodic lactonisation reaction. ${ }^{[a][b][c]}$ [a] Reaction conditions: 0.6 $\mathrm{mmol}(1), 5$ eq. $\mathrm{R}^{1} \mathrm{COOH}, 1$ eq. $\mathrm{KOH}, \mathrm{MeOH}$, Pt foil working electrode, Ptplated counter electrode, $100 \mathrm{~mA} \cdot \mathrm{cm}^{-2}, 10 \mathrm{~F} \mathrm{~mol}^{-1}, \mathrm{RT}, 56 \mathrm{~min}$. [b] Yield determined by ${ }^{1} \mathrm{H}$ NMR spectroscopic analysis of the crude mixture using $\mathrm{CH}_{2} \mathrm{Br}_{2}$ as an internal standard. [c] Isolated yields in parentheses.

Using the newly developed method, a range of $\mathrm{Y}^{-}$ substituted lactones were obtained in good yields (lactones 2 10). Furthermore, it appears that the steric bulk of the carboxylic acid has little to no effect on the coupling, with no notable decrease in yield upon exchange of butyric acid for iso-butyric or 3,3-dimethylbutyric acid.

Ester-functionalised lactones were also synthesised $(\mathbf{8}, \mathbf{9})$ with no undesired electrochemical overoxidation observed by ${ }^{1} \mathrm{H}$ NMR spectroscopy. More notably, it was possible to install halogen-terminated alkyl chains into these systems (10), which are rarely tolerated by more conventional radical methodologies owing to the ease of competitive halide radical abstraction. Similarly, the synthesis of lactones using a secondary co-acid was successful (7) albeit in slightly lower yields, which is unsurprising given the ease with which secondary alkyl radicals are usually anodically overoxidised to give the corresponding carbocations. ${ }^{[44,45]}$

The possibility of synthesising higher functionalised lactones through modification of the hemioxalate salt was then explored (Scheme 3). Incorporation of alkyl moieties in the $\alpha$ position was achieved using the same synthetic procedure as for 2-10, resulting in the synthesis of the alkyl lactones 11 and 12, alongside the more complex spiro-lactone 13. The addition of substituents on the alkene in the starting material allowed further $\mathrm{Y}$-functionalisation and the introduction of $\mathrm{C}_{1}$-substituents on the alkyl chain, with the latter, also demonstrating the applicability of the electrochemical methodology to substituted alkenes.

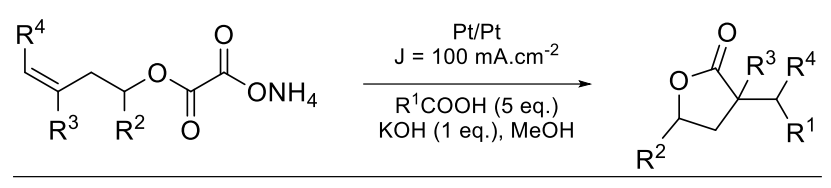

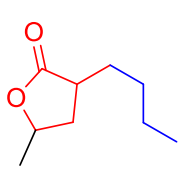<smiles>CC1CC(CCCCl)C(=O)O1</smiles>

11

$40 \%(23 \%)$

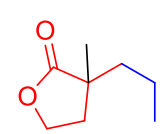

14 $63 \%(24 \%)$<smiles>C1CCCCC1</smiles>

15

$79 \%(50 \%)$<smiles>CCCCC1CCCOC1=O</smiles>

17

$31 \%(28 \%)$

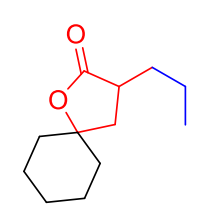

13

$40 \%(31 \%)$

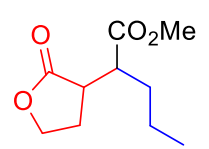<smiles>COC(=O)C(CCCl)C1CCOC1=O</smiles>

16

$73 \%(52 \%)$
Scheme 3. Scope for further functionalisation. ${ }^{[a][b][c]}[\mathrm{a}]$ Reaction conditions: $0.6 \mathrm{mmol}$ (1), 5 eq. $\mathrm{R}^{1} \mathrm{COOH}, 1$ eq. $\mathrm{KOH}, \mathrm{MeOH}, \mathrm{Pt}$ foil working electrode, Ptplated counter electrode, $100 \mathrm{~mA} \cdot \mathrm{cm}^{-2}, 10 \mathrm{~F} \mathrm{~mol}^{-1}, \mathrm{RT}, 56 \mathrm{~min}$. [b] Yield determined by ${ }^{1} \mathrm{H}$ NMR spectroscopic analysis of the crude mixture using $\mathrm{CH}_{2} \mathrm{Br}_{2}$ as an internal standard. [c] Isolated yields in parentheses.

Furthermore, the applicability of the methodology to the synthesis of $\delta$-valerolactones was briefly investigated. Indeed, modification of the hemioxalate salt resulted in the successful formation of $\delta$-valerolactone $\mathbf{1 7}$ in moderate yields under similar conditions, demonstrating the versatility of this electrochemical method.

Similar attempts were made towards the synthesis of gamma-substituted lactams using this method. Under electrochemical conditions, oxamic acids typically give the corresponding isocyanate, rather than the desired acyl radical. This is believed to arise because the formation of the carbocation is much more favourable, due to resonance stabilisation from the nitrogen lone pair. It was postulated that the introduction of electron-withdrawing functionality (e.g. tosylate) on nitrogen would preclude lone pair donation and thus facilitate radical formation. However, upon electrolysis of 18, no evidence of exo-cyclisation was found. Instead, competitive overoxidation was observed, followed by trapping with methoxide to afford the corresponding carbamate 20 (Scheme 4). A similar overoxidation also occurred even when a stronger electron-withdrawing group, such as a triflate, was installed on the nitrogen centre. A comprehensive study of the nitrogen systems is on-going and will be reported in due course. 
<smiles>[R1]CC1CCN([13CH2])C1=O</smiles>

18
Scheme 4. Competing reaction pathways after decarboxylation of hemioxalate salt 18 to form carbamate 20 . $\mathrm{Ts}=\mathrm{SO}_{2}-\mathrm{C}_{6} \mathrm{H}_{4}-p-\mathrm{CH}_{3}$.

In summary, we have reported a novel electrochemical methodology to generate oxycarbonyl radicals from simple hemioxalates. The methodology was applied to the synthesis of lactones via an intramolecular capture of the radical, followed by an $s p^{3}-s p^{3}$ radical cross-coupling. The reaction proceeds rapidly under mild and green conditions, without the need for transition metal catalysts, and is also tolerant of a variety of functional groups. Furthermore, it was possible to extend this methodology to the synthesis of substituted lactones $\delta$-valerolactones, which further demonstrates the high versatility of this electrosynthetic procedure.

\section{Acknowledgements}

The authors are grateful to the Engineering and Physical Sciences Research Council (Grant EP/S017097/1 to KL and $\mathrm{MCL}$ ) for their financial support, the University of Greenwich (Vice Chancellor's PhD Scholarship to AP), the University Alliance "Applied Biosciences for Health" Doctoral Training Alliance (PhD scholarship to $A G)$, and IKA for their material support (to KL).

Keywords: Electrochemistry • Electrosynthesis • Green Chemistry $\cdot$ Lactones $\cdot$ Radical Cyclisation

[1] M. Faraday, Philos. Trans. R. Soc. London 1832, 122, 125-162.

[2] H. Kolbe, Justis Liebigs Ann. Chem. 1849, 69, 257-294.

[3] M. Yan, Y. Kawamata, P. S. Baran, Angew Chem Int Ed 2018, 57 , 4149-4155.

[4] C. G. W. van Melis, M. R. Penny, A. D. Garcia, A. Petti, A. P. Dobbs, S. T. Hilton, K. Lam, ChemElectroChem 2019, DOI 10.1002/celc.201900815

[5] K. Lam, I. E. Markó, Synlett 2012, 23, 1235-1239.

[6] X. Luo, X. Ma, F. Lebreux, I. E. Markó, K. Lam, Chem. Commun 2018, 54, 9969-9972.

[7] K. Lam, W. E. Geiger, J. Org. Chem. 2013, 78, 8020-8027.

[8] X. Ma, D. F. Dewez, L. Du, X. Luo, M. E. István, K. Lam, J. Org. Chem. 2018, 83, 12044-12055

[9] E. J. Horn, B. R. Rosen, Y. Chen, J. Tang, K. Chen, M. D. Eastgate, P. S. Baran, Nature 2016, 533, 77-81.

[10] B. K. Peters, K. X. Rodriguez, S. H. Reisberg, S. B. Beil, D. P. Hickey, Y. Kawamata, M. Collins, J. Starr, L. Chen, S. Udyavara, K. Klunder, T. J. Gorey, S. L. Anderson, M. Neurock, S. D. Minteer, P. S. Baran, Science 2019, 363, 838-845.

[11] Y. Takahira, M. Chen, Y. Kawamata, P. Mykhailiuk, H. Nakamura, B. K. Peters, S. H. Reisberg, C. Li, L. Chen, T. Hoshikawa, T.
[12]

[13]

[15]

[16]

Shibuguchi, P. S. Baran, Synlett 2019, 30, A-E.

K. Lam, I. E. Markó, Org. Lett. 2011, 13, 406-409.

O. Hammerich, B. Speiser, Organic Electrochemistry: Revised and Expanded, CRC Press, 2015

R. A. Momin, M. G. Nair, J. Agric. Food Chem. 2001, 49, 142-145.

S. K. Murphy, V. M. Dong, J. Am. Chem. Soc 2013, 135, 5553-5556.

G. A. Kraus, B. Roth, 1978, 43, 4923-4924.

D. Singh, N. Devi, V. Kumar, C. C. Malakar, S. Mehra, S. Rattan, R. K. Rawal, V. Singh, Org. Biomol. Chem. 2016, 14, 8154-8166.

[18] K. Gach, A. Janecka, Anticancer. Agents Med. Chem. 2014, 14, 688-694.

[19] L. Yi, M. L. Bandu, H. Desaire, Anal. Chem. 2005, 77, 6655-6663.

[20] B. Mao, M. Fañanás-Mastral, B. L. Feringa, Chem. Rev. 2017, 117, 10502-10566.

[21] F. A. Larik, A. Saeed, D. Shahzad, M. Faisal, H. El-Seedi, H. Mehfooz, P. A. Channar, Steroids 2017, DOI

10.1016/j.steroids.2016.12.010

[22] X. Xie, S. S. Stahl, J. Am. Chem. Soc 2015, 137, 3767-3770.

[23] L. Huang, H. Jiang, C. Qi, X. Liu, J. Am. Chem. Soc 2010, 132, 17652-17654.

[24] I. Triandafillidi, M. G. Kokotou, C. G. Kokotos, Org. Lett. 2017, 2018, 36-39.

[25] M. Zheng, P. Chen, L. Huang, W. Wu, H. Jiang, Org. Lett. 2017, 19, 5756-5759.

[26] T. P. Montgomery, A. Hassan, B. Y. Park, M. J. Krische, J. Am. Chem. Soc 2012, 134, 11100-11103.

[27] L. E. Overman, N. A. Weires, Y. Slutskyy, Angew. Chemie Int. Ed. 2019, 58, 8561-8565.

[28] J. Mulzer, in Org. Synth. Set (Ed.: H Waldman), John Wiley \& Sons Ltd, 2008, pp. 158-164

[29] F. Boratyński, A. Janik-Polanowicz, E. Szczepańska, T. Olejniczak, Sci. Rep. 2018, 8, 468-478.

[30] H. Xie, J. Lu, Y. Gui, L. Gao, Z. Song, Synlett 2017, 29, 2453-2459.

[31] C. Raviola, S. Protti, D. Ravelli, M. Fagnoni, Green Chem. 2019, 21 , 748-764.

[32] H. Togo, M. Fujii, M. Yokoyama, Bull. Chem. Soc. Jpn. 1991, 64, 57-67.

[33] M. D. Bachi, E. Bosch, J. Org. Chem. 1992, 57, 4696-4705.

[34] H. J. Schäfer, R. Pistorius, Angew. Chem. Int. Ed. 1972, 11, 841842.

[35] A. Weiper, G. Dralle, M. Aus dem Kahmen, T. Luebbers, E. Klocke, H. J. Schäfer, Dechema Monog. 1992, 125, 595-612.

[36] Based on the assumption of 1 mole of electrons, supplied at $240 \mathrm{~V}$ at the average cost per kWh in the UK ( $£ 0.13$ per kWh).

[37] Costs based upon listings on Sigma Aldrich website, June 2019.

[38] D. Hayrapetyan, V. Shkepu, O. T. Seilkhanov, Z. Zhanabil, K. Lam, Chem. Commun. 2017, 53, 8451-8454.

[39] See supporting information for details of cyclic voltammetry studies. [40] See supporting information for details of initial optimisation studies.

[41] A. Matzeit, H. J. Schäfer, C. Amatore, Synthesis, 1995, 11, 1432-1444

[42] H. J. Schäfer, in Electrochem. IV (Ed.: E. Steckhan), Springer, Berlin, 1990, pp. 91-151

[43] J. Richers, M. Heilmann, M. Drees, K. Tiefenbacher, Org. Lett. 2016, 18, 6472-6475.

[44] H. G. Thomas, Angew Chem Int Ed 1971, 10, 557-558.

[45] G. E. Svadkovskaya, S. A. Voitkevich, Russ. Chem. Rev. 1960, 29, 161-180. 



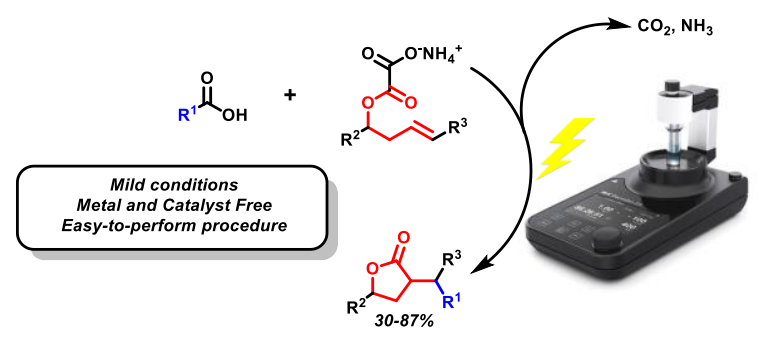

Alessia Petti, Matthew C. Leech,

Anthony D. Garcia, , lain C. A. Goodall, Adrian P. Dobbs, and Kevin Lam*

Page No. - Page No.

Economical, Green, and Safe Route Towards Substituted Lactones by Anodic Generation of Oxycarbonyl Radicals 